\title{
VARIANT ORIGIN OF AN ARTERIAL TRUNK FROM AXILLARY ARTERY CONTINUING AS PROFUNDA BRACHII ARTERY-A UNIQUE ARTERIAL VARIATION IN THE AXILLA AND ITS CLINICAL IMPLICATIONS
}

\author{
Kumar Naveen ${ }^{1}$, Patil Jyothsna ${ }^{1}$, Nayak Satheesha $\mathbf{B}^{1}$, Mohandas Rao KG ${ }^{1}$, \\ Swamy Ravindra $S^{1}$, Deepthinath $\mathbf{R}^{1}$, Shetty Surekha $\mathbf{D}^{1}$
}

\section{ABSTRACT}

BACKGROUND: Axillary artery is known to show different variations mostly in its branching pattern. Similarly, the origin of profunda brachii is often encountered with abnormality. Therefore, when the vascular variations in the upper limb persist, mostly it is confined to its branching pattern followed by its variant origin. But, among all the reported variations of profunda brachii, its variant origin from the $3 r d$ part of the axillary artery with common trunk for the branches of axillary artery is unique.

CASE DETAILS: We report here an anomalous origin of profunda brachii as continuation of an arterial trunk arising from 3rd part of the axillary artery. This common trunk at its commencement passed between 2 roots of median nerve and gave branches of 3rd part of axillary artery before it continued as profunda brachii artery. The further course and branching pattern of profunda brachii were normal. CONCLUSION: Since the axillary artery is next choice of artery for arterial canulation in cardiopulmonary bypass procedures, prior knowledge of existence of such variation in its branching pattern helps in avoiding possible diagnostic or interventional therapeutic errors.

KEYWORDS: axillary artery, common trunk, profunda brachii, vascular variation

\section{DOI: http://dx.doi.org/10.4314/ejhs.v24i1.13}

\section{INTRODUCTION}

Axillary artery, a vascular content of the axilla, is a direct continuation of subclavian artery extending from the outer border of the first rib to the lower border of teres major. On its forward course in the axilla, it is in intimate relation with the cords and branches of brachial plexus. For description purpose, it is divided into three parts by the pectoralis minor as it crosses superficially from medial to lateral aspect of the artery. From its 3 parts, normally it gives six branches with the dictum of the $1^{\text {st }}$ part one branch-superior thoracic artery, $2^{\text {nd }}$ part 2 branches-lateral thoracic and thoraco-acromial branches, and $3^{\text {rd }}$ part gives 3 branches-anterior and posterior circumflex humeral branches and subscapular artery. The number of branches may vary as two or more branches often arise as a single trunk or smaller branches may arise separately instead of from its parent trunk. Axillary artery then continues as brachial artery. But in rare occasion, it may bifurcate into 2 branches-one being more superficial in course than the other. In this condition, they are often referred to as the doubling of brachial artery (1). Profunda brachii artery is the most prominent branch of brachial artery and courses into radial groove of the humerus along with radial nerve.

Axillary artery is the second next artery to be lacerated by violence and thus is more susceptible to diseases. Sufficient knowledge of variant branching pattern of these vessels is important in the field of reparative surgery as well as during angiography procedures (2).

\footnotetext{
${ }^{1}$ Department of Anatomy, Melaka Manipal Medical College (Manipal campus), Manipal University, Karnataka, INDIA Corresponding Author : Kumar Naveen, Email : naveentonse@gmail.com
} 


\section{CASE REPORT}

During the dissection classes for Medical Undergraduate Students, we noticed a variation in the branching pattern of axillary artery. The variation was unilateral and observed in the axilla of right limb of a male cadaver aged about 60 years. The branching patterns of its proximal two parts were normal. An arterial trunk was given off from its third part and it coursed backwards and downwards passing between 2 roots of median nerve. The diameter of this trunk was equal to the remaining part of the parent artery (Fig. 1). This anomalous arterial trunk gave all 3 branches of $3^{\text {rd }}$ part of axillary artery before it continued as profunda brachii artery (Fig. 2). Further course and branching pattern of profunda brachii were normal.

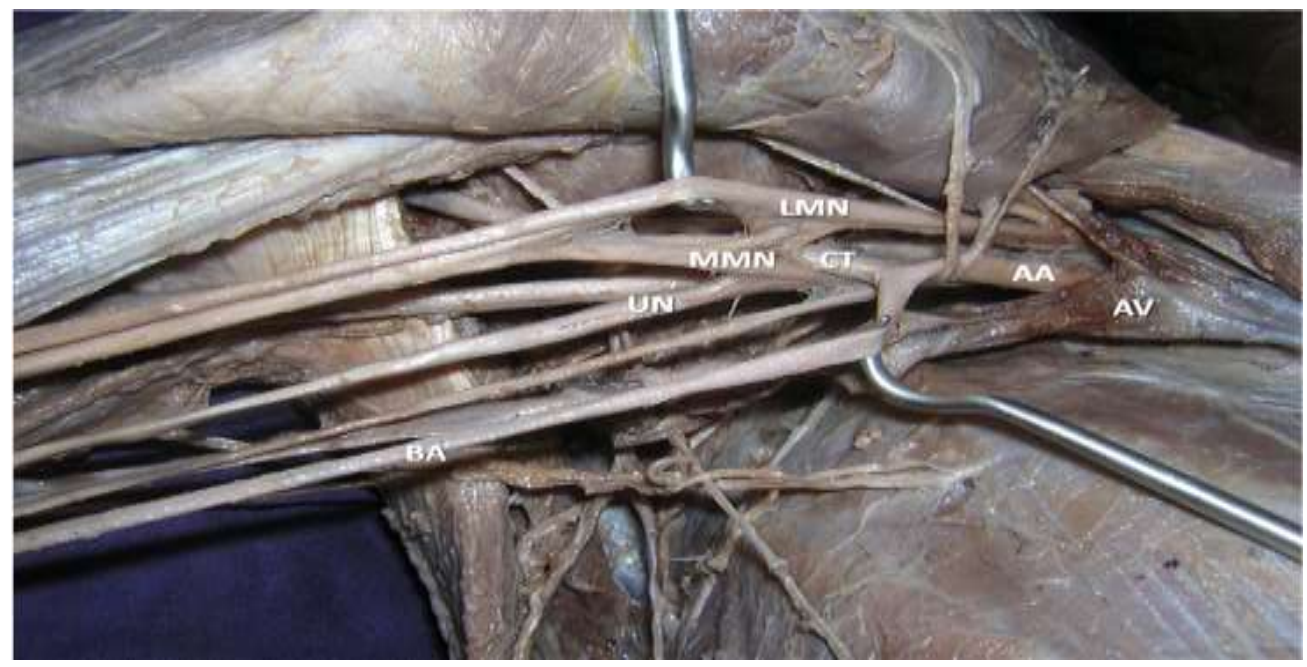

Figure 1: Dissection of right axilla showing origin of common trunk (CT) from axillary artery (AA) and passing between medial $(M M N)$ and lateral (LMN) roots of median nerve. UN: ulnar nerve, AV: axillary vein and BA: brachial artery

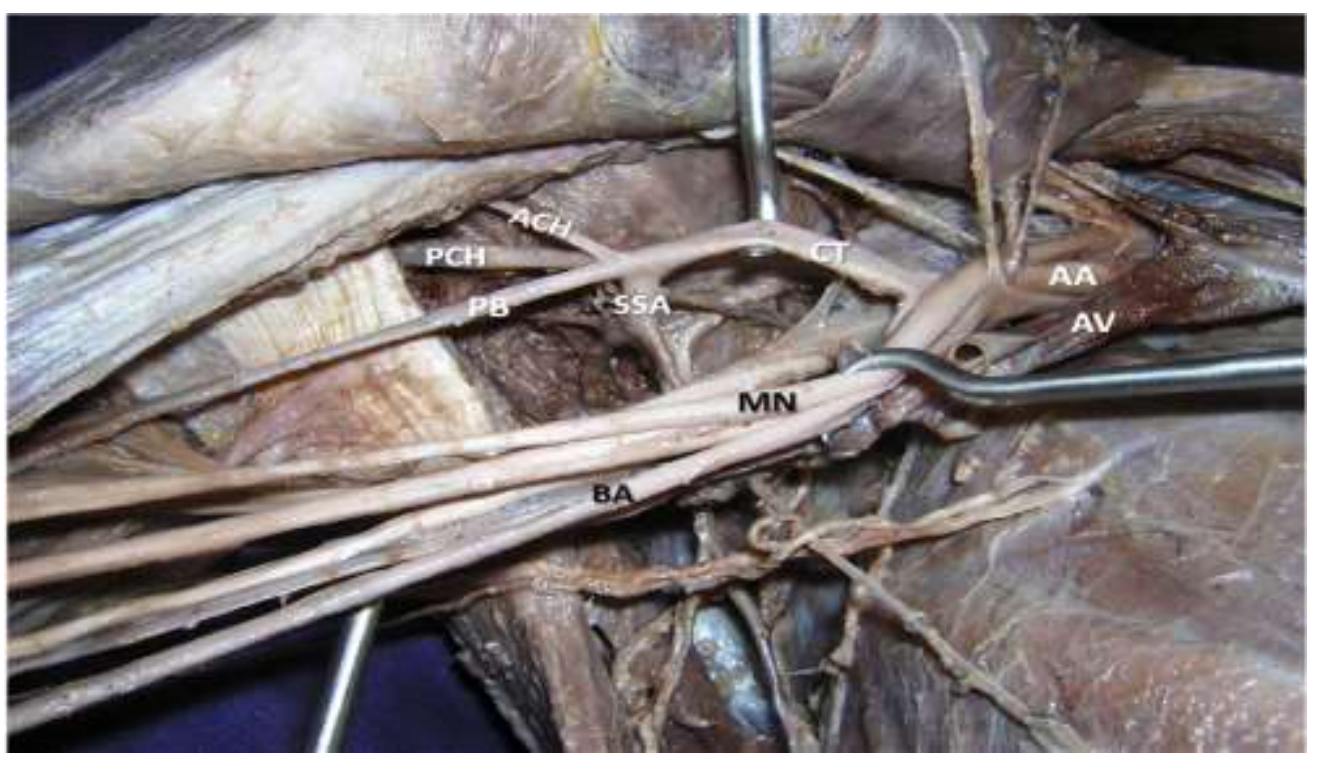

Figure 2: Branching pattern of common trunk (CT) arising from axillary artery (AA) and then continuing as profunda brachii artery (PB). BA: Brachial artery, SSA: Subscapular artery, ACH: anterior circumflex humeral artery, PCH: posterior circumflex humeral artery. MN: median nerve, AV: Axillary vein. 


\section{DISCUSSION}

The vascular variations in the upper limb are fairly common and reported extensively. Among these, the reported cases of unusual branching pattern of axillary artery mimicking the present case but with exceptions are discussed herewith.

George et al. (3) reported the origin of a common trunk from axillary artery and giving rise to common circumflex humeral-subscapular trunk and then continuing as profunda brachii artery as observed in our case. However, there is no evidence of coursing of this variant arterial trunk between the median nerve roots, which we report here.

In another case reported by Sawant et al. (4) the axillary artery divided immediately after its commencement into 2 divisions: superficial and deep. The superficial division continued as brachial artery and deep division performed the role of axillary artery by giving all its named branches then it continued as profunda brachii artery. Hence, in this case, common trunk was literally replacing the whole of the axillary artery before it further coursing as profunda brachii artery.

Ramesh et al. (5) also observed a very similar case of common trunk like ours including its course through the median nerve root and giving branches of $3^{\text {rd }}$ part of axillary artery. This common trunk gave rise to profunda brachii artery then continued forwards and terminated by dividing into superior and inferior ulnar collateral arteries. Contrary to our case, here the profunda brachii artery took origin from the variant arterial trunk and further had variant branching pattern.

Samuel et al. (6) identified a case of an abnormal arterial trunk originating from 3rd part of axillary artery giving multiple branches which are supposed to be arising from both axillary and profunda brachii arteries together. Hence, in this case, classical profunda brachii was absent. Therefore, though there are a number of reports on variety of abnormal branching pattern of axillary artery, each report exhibits its own unique variant pattern. Probably, the first report in the literature about the origin of common trunk passing between 2 roots of median nerve was by Kogan and Lewinson (7) in 1998.

Third part of the axillary artery is known to show its variant branching pattern. It includes, two circumflex humeral arteries arising from single trunk or together with profunda brachii or together with subscapular artery etc (8).

Embryologically, axillary artery represents axial system of development together with brachial and anterior interosseous arteries. In later stages of development, superficial brachial artery from axillary artery develops and it continues as radial artery. However, the definitive radial artery develops as a result of regression of median artery and anastomoses between brachial and superficial brachial arteries with the regression of proximal segment of superficial brachial artery $(9,10)$.

These variations mark a significant importance during axillary approach in shoulder joint dislocations, where it requires precaution during transverse incision to avoid injury to such a variant common arterial trunk and its branches (11). The percentage incidence of presence of bilateral common subscapular-humeral trunk from $3^{\text {rd }}$ part of the axillary artery is $3.8 \%$ and bilateral thoracohumeral trunk is $1.9 \%$ as reported by Saeed et al. (12). Rare case of presence of bilateral double axillary artery was reported by Jurjus et al. (13). Since the axillary artery is in close relation with the cords of brachial plexus, during surgical repair of brachial plexus, it is very important to have the knowledge of such anomalous arterial trunk of axillary artery to prevent bleeding (14). This knowledge also plays a crucial role during radio-diagnostic techniques in case of various traumatic injuries (15).

In an alternative approach of femoral arterial cannulation, the right axillary artery is preferred in the presence of aortic or iliofemoral disease. This practice proved to be a safe and effective means to provide adequate blood supply during cardiopulmonary bypass procedures (16). Therefore, deep understanding of all possible variant branching patterns of axillary artery is useful to the cardio-vascular surgeons. 


\section{REFERENCES}

1. Hollinshed, W. H. \& Rosse, C. Text Book of Anatomy. 4th Ed. Harper \& Row, Philadelphia, 1985. pp.187-9.

2. Yoshinaga K, Kodama K, Kameta K et al. A rare variation in the branching pattern of the axillary artery. Indian J. Plast. Surg 2006;39:222-3.

3. George B. M, Nayak S \& Kumar P. Clinically significant neurovascular variations in the axilla and the arm - a case report. Neuroanatomy2007; 6(1):36-8.

4. Sawant SP, Shaikh ST, More RM. Variant axillary artery - A case report. IJCRR 2012; 4(21): 102-108.

5. Ramesh Rao T, Shetty $P$ and Suresh R. Abnormal branching pattern of the axillary artery and its clinical significance. Int. J. Morphol 2008;26(2):389-392.

6. Samuel VP, Vollala VR, Nayak S, Rao M, Bolla SR, Pammidi N. A rare variation in the branching pattern of the axillary artery. Indian J Plastic Surg 2006; 39: 222-3.

7. Kogan I \& Lewinson D. Variation in the branching of the axillary artery. A description of a rare case. Acta Anat 1998; 162(4):238-40.

8. Bergman R. A, Thomson S. A, Afifi A. K \& Saadeh, F.A. Compendium of Anatomic Variation. In Cardiovascular system.
Baltimore, Urban and Schwarzenber 1988, pp. 72-3.

9. Senior H.D. A Note on the Development of the Radial Artery. The Anatomical Record 1926; 32: 220-221.

10. Singer E. Embryological pattern persisting in the arteries of the arm. The Anatomical Record. 1933; 55: 403-409.

11. McGregor Lee A. Lee McGregor's Synopsis of Surgical Anatomy.12th Revised Ed. Hodder Arnold, 1986,644.

12. Saeed M, Rufai AA, Elsayed SE, Sadique MS. Variations in the subclavian-axillary arterial system. Saudi Med J. 2002; 23(2): 206-212.

13. Jurjus A. R, Correa-De-Aruaujo R \& Bohn R. C. Bilateral double axillary artery: embryological basis and clinical implications. Clin. Anat 1999; 12(2):135-40.

14. Samuel L. Turek. Turek's Orthopaedics: Principles and Their Application. 5th Ed. Lippincott Williams \& Wilkins, 1994, 708.

15. Sharadkumar Pralhad Sawant, Shaguptha T. Shaikh, Rakhi Milind More. The Study of variations in the branches of axillary artery. Int. J. Adv Phy and All Sci 2012; 1(1) 1-7.

16. John Kokotsakis, George Lazopoulos, Michael Milonakis et al. Right axillary artery cannulation for surgical management of the hostile ascending aorta; Tex Heart Inst J. 2005; 32(2):189-193. 